Blood

Purification

\section{Publisher's Note}

Blood Purif 2020;49:385

DOI: $10.1159 / 000509634$

Karger Publishers is dedicated to "Connecting and Advancing Health Sciences", which brings our new strategy to the point. This is also reflected in our new brand appearance including a new cover design.

On our new covers "Advancing" is expressed in the simplicity, in being modern and more suitable for digital use, while "Connecting" refers to summarizing the most important journal information and offering guidance through our portfolio. This year we will be rolling out our new design across all journals and we are delighted to unveil the first new cover of Blood Purification in this issue.

Changing the covers is one step to spark exciting new ideas and advance into a new decade of scientific publishing. Finally, we would like to take this opportunity to thank you, our editors, authors, reviewers, and readers, for your continued commitment which contributes to the success of Blood Purification and the Health Sciences it represents.

Gabriella Karger, Chairwoman \& Publisher Daniel Ebneter, CEO 